\title{
Women's Perceptions and Attitudes Related to Family Planning Use among Poor Population in Rural Rwanda
}

\author{
Costase Ndayishimiye \\ Faculty of Medicine, Public Health Sciences (Europubhealth+), Université de Liège, Liège, Belgium \\ Email: ncostase@gmail.com
}

How to cite this paper: Ndayishimiye, C. (2021) Women's Perceptions and Attitudes Related to Family Planning Use among Poor Population in Rural Rwanda. Advances in Reproductive Sciences, 9, 1-12.

https://doi.org/10.4236/arsci.2021.91001

Received: June 14, 2020

Accepted: December 13, 2020

Published: December 16, 2020

Copyright $\odot 2021$ by author(s) and Scientific Research Publishing Inc. This work is licensed under the Creative Commons Attribution International License (CC BY 4.0).

http://creativecommons.org/licenses/by/4.0/

(c) (i) Open Access

\begin{abstract}
INTRODUCTION: In 2012, Rwandan Government has declared family planning (FP) a national priority for poverty reduction and socioeconomic development. However, rural areas still contribute to higher fertility rates. OBJECTIVE: To explore factors to influence FP uptake in rural families. METHODS: This study used mixed (quantitative and qualitative) methods consisted of two separate surveys. The first survey (quantitative-based cross-sectional design) determined FP use in households while the second survey (qualitative-based design) identified socio-cultural factors which hindered FP uptake in households. In total, 119 households with women in reproductive age $(15-45)$ were targeted in rural areas in Western province, Karongi District. The data collected during door-to-door visits using paper-based-questionnaires and administered through interviews. A database mask was designed under OnaCollect, then processed in SPSS software. The results were presented in tables of frequencies, the difference between proportions assessed using Chi-Square-test, the difference between means assessed using t-tests, significance at $\mathrm{p}=$ or $<0.05$, confidence level at 0.95 , and a margin error of 0.09. RESULTS: Socio-cultural norms influenced no use of contraception $(32.8 \%)$ or only promoted natural methods $(12.6 \%)$. Social norms were religious in origin (38.5\%) where Christianity (91.8\%) discouraged modern methods (viewed as killing children) but encouraged using natural methods, preferably abstinence (73.3\%). Cultural norms (17.9\%) influenced families to have many children as resources of wealth, evidence of productivity, and a way to decrease parents' workloads including assisting mothers in home-based activities such as cooking, and assisting fathers in farming activities such as keeping cows, goats and pigs. Other attitudes included gender-based issues (2.5\%) mainly due to spousal disapproval (men dominated in taking FP decisions in families), whereas other non-users of modern methods $(28.2 \%)$ feared side-effects. This study was registered with
\end{abstract}


IRB: CMHS/IRB/097/2019. CONCLUSION: Religious, social, and cultural norms affect FP in rural areas. In order to accelerate FP uptake, men and religious leaders should be targeted as key partners who influence women's choices.

\section{Keywords}

Family Planning in Rwanda, Religion and Family Planning, Contraceptive Methods, Community Health Workers in Rwanda

\section{Background}

Contraception use is increasing throughout the world. The prevalence has increased from $54.8 \%$ in 1990 to $63.3 \%$ in 2010 and increasing contraceptive use has decreased the amount of maternal deaths by $40 \%$ over the past 20 years. Typically, contraceptive prevalence is higher in countries where there is greater access and availability of contraceptive methods [1]. Contraception non-use is one of the most direct causes of unintended pregnancies in low- and middle-income countries [2]. Fertility and future projected population growth are much higher in sub-Saharan Africa (SSA) than in any other region of the world [3]. There are approximately 213 million women in Sub Saharan Africa. Of those women, $89 \%$ would like to avoid pregnancy and $60 \%$ have an unmet need for contraception [4]. The contraceptive prevalence rate (CPR) in Rwanda felt after the 1994 genocide of Tutsi, from 13\% in 1992 to only 4\% in 2000 [5]. By 2005, the contraceptive prevalence was $17 \%$ for any method and $10 \%$ for any modern method. There was higher use of modern contraceptive methods in urban areas vs. rural (21\% vs. 9\%) [5]. The Economic Development and Poverty Reduction Strategy (EDPRS) 2008-2012 laid out ambitious goals, including reaching a contraceptive prevalence rate of $70 \%$ by 2012, and then the Rwandan Government committed to achieving the Millennium Development Goals by 2015 and has declared Family Planning (FP) a national priority for poverty reduction and socioeconomic development of the country [5]. In 2012, Rwanda committed to ensuring the availability of family planning services in each of the 14,841 Rwanda administrative villages (Imidugudu) through delivery by the 45,000 community health workers (CHWs). This has helped Rwanda to expand existing information and dissemination programs about family planning to the general public and CHWs increase awareness of the various choices available. To focus on convenience and reduce the frequency of visits to health providers, the government of Rwanda has introduced long-lasting contraceptive methods, including permanent ones, and high-quality integrated family planning services in every hospital and health center [6]. Despite all those interventions, research shows that rural areas continue to contribute to high birth rates. There exist misperceptions, socio-cultural and religious influences that affect FP service demand from the rural population [6]. The government of Rwanda is committed to improve 
awareness and create demand for family planning among its population, including poor rural population, so that, by 2024 , total demand for family planning will have increased from $72 \%$ to $82 \%$ [6]. However, this research study falls in line of the Rwandan Government to conduct new studies to inform policies, strategy formulation and evidence-based programming for high impact interventions to achieve family planning goals [7]. Hence we conducted this study to identify sociocultural perceptions and attitudes that hinder family planning use in rural Rwanda communities, and then to explore factors to influence rural people's perceptions and behavior shifts in favor of contraceptive use and smaller family size to take advantage of smaller families in terms of health and educational opportunities.

\section{Methods}

\subsection{Study Settings}

This study has been conducted from December 2018 to August 2019 in Rwanda. Rwanda has 30 administrative Districts. According to Demographic Health Survey (DHS) 2014-2015, the use of contraception by women in Rwanda reached $53 \%$ whereby regional variations in the use of any method were the least in the West (47\%). Karongi district has $62.1 \%$ of the resident population aged under 25 years and $48.9 \%$ are $0-17$ years, reflecting the high level of fertility in the recent past. In this District, it has been shown that rural areas have high fertility rates compared to urban areas. By distribution count of the resident population of Karongi District, Rwankuba areas have 37,802 population, making them the first populated places in the Karongi District, therefore for the purpose of our research, we have selected top 3 rural areas, namely Munini, Bigugu and Nyarusanga.

\subsection{Study Design}

We used a mixed quantitative and qualitative methodology (two designs). The quantitative-based cross-sectional design determined FP use in households and the qualitative-based design identified socio-cultural factors which hindered FP uptake in households. Participation in the survey was entirely voluntary and anonymous.

\subsection{Population and Sampling}

The aim was to obtain responses from 119 households with women in reproductive ages (15 to 45 years old) in 3 study sites (Munini, Bigugu and Nyarusanga). To obtain the sample size, an online calculator (accessible here) has been used.

\subsection{Inclusion and Exclusion Criteria}

Only participants with permanent residence in the household were considered. Permanent residence defined in this study as any person who lived in any of the three study sites for at least 5 years. The study excluded participants who 
thought their participation could be distressing and those under 15 years of age.

\subsection{Data Collection and Management}

We collected during door-to-door household visits in the 3 selected sites, based on the availability of targeted participants. We used paper-based questionnaires, administered through interviews. The questionnaires have been designed specifically for the purpose of the study and were piloted for comprehensibility. The database mask was designed under OnaCollect, then, encoded by smartphone, compiled online by OnaCollect and exported from Excel to SPSS software (version 23.0) for processing. The Excel spreadsheet was protected by a password and the survey forms were kept safe.

\subsection{Data Analysis}

The results were presented in tables of frequencies, differences between proportions assessed using Chi-Square-test while those between means assessed using t-tests, significance at $\mathrm{p}=$ or $<0.05$, confidence level at $0.95(95 \%)$ and margin error of $0.09(9 \%)$.

\subsection{Ethical Considerations}

We sought ethical clearance from the Institutional Review Board (IRB) of the University of Rwanda (College of Medicine and Health Sciences). Consent forms were specifically designed, translated in local language (Kinyarwanda) and information collected was anonymized. No significant risk factors have been identified apart from social and emotional risks that might have resulted from the memory of children who have died or were not living with their parents. These emotional risks included anxiety and stigma. They were mitigated by always reminding participants that they had the right to withdraw from research or to limit their participation if they become uncomfortable.

\section{Results}

\subsection{Number of Children per Household}

As shown in Table 1, in households there were 5 children or above for those families which have not used any family planning method and 1 to 3 children for those who used a contraceptive method.

\subsection{Participants Age versus Number of Children}

In respective age groups, women had many children as illustrated in Figure 1. The majority who had 1 - 2 children were in 20 - 24 years, 3 - 4 children in 25 29 years, 5 - 6 children in 30 - 34 years, and those with at least 7 children were 35 years or above.

\subsection{Contraception Users: Modern vs. Traditional Methods}

1) Modern methods Users 
Table 1. The number of children per household vs status of family planning use in respective households.

\begin{tabular}{ccccc}
\hline $\begin{array}{c}\text { Number of } \\
\text { children in } \\
\text { household }\end{array}$ & $\begin{array}{c}\text { Never Used } \\
\text { Family Planning } \\
\text { Methods }\end{array}$ & $\begin{array}{c}\text { Used Modern } \\
\text { Family Planning } \\
\text { Methods }\end{array}$ & $\begin{array}{c}\text { Used Traditional } \\
\text { Family Planning } \\
\text { Methods }\end{array}$ & $\begin{array}{c}\text { Number of } \\
\text { households }\end{array}$ \\
\hline 0 Children & 1 & 0 & 0 & 1 \\
1 - 2 Children & 9 & 15 & 3 & 27 \\
3 - 4 Children & 13 & 28 & 2 & 43 \\
5 - 6 Children & 18 & 7 & 2 & 27 \\
7 and above & 16 & 5 & 0 & 21 \\
Total & 57 & 55 & 7 & 119 \\
\hline
\end{tabular}

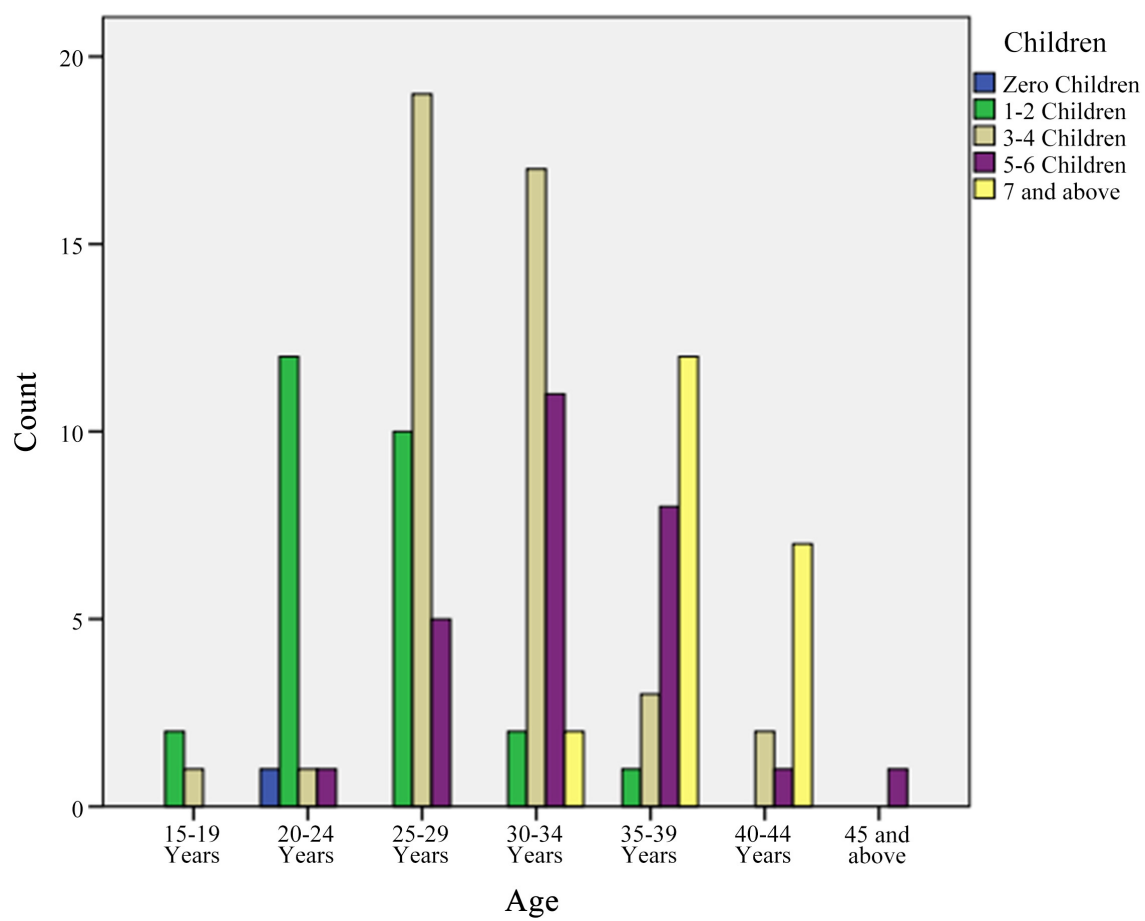

Figure 1. Represents age range of women in households vs number of children.

Women (54.6\%) used modern contraceptives as shown in Table 2. Injectables were the mostly used methods (44.6\%), followed by Jadelle $(24.6 \%)$ and pills (13.8\%). The least used methods were sterilization $(3.1 \%)$, IUDs $(4.6 \%$,) and condoms (9.2\%).

\section{2) Traditional methods}

$12.6 \%$ reported traditional methods: abstinence (73.3\%), withdrawal (13.3\%), and folkloric (13.3\%).

\subsection{Contraception Nonusers: Reasons Influenced to Have Large Family Sizes Were Summarized below (Table 3)}

1) Persisted high fertility-sustaining socio-cultural factors 
Table 2. Modern methods of contraception commonly used in FP users.

\begin{tabular}{ccc}
\hline Type of modern methodern used & No of households & Percentage (\%) \\
\hline Injections & 29 & 44.6 \\
Jadelle & 16 & 24.6 \\
IUD & 3 & 4.6 \\
Pills & 9 & 13.8 \\
Condoms club & 6 & 9.2 \\
BTL & 2 & 3.1 \\
\hline
\end{tabular}

Table 3. Reasons influenced to have large family sizes.

\begin{tabular}{ccc}
\hline Reasons for non-users of contraception & Frequency & Percentage (\%) \\
\hline Cultural beliefs & 7 & 17.9 \\
Religious reasons & 15 & 38.5 \\
Fear of side effects & 11 & 28.2 \\
Lack of knowledge of FP & 2 & 5.1 \\
Poor knowledge of FP & 3 & 7.7 \\
Traditional beliefs & 1 & 2.5 \\
\hline
\end{tabular}

Non-contraception users, $17.9 \%$ reported socio-cultural reasons. Larger families were seen as socially favorable to maintain pride, hence FP viewed negatively. Women showed sustained beliefs to increase family size as resources of wealth and evidence for family productivity.

“Kugira abana benshi ntibigira uko bisa, kuko abana ni amaboko" ... "Kandi bigaragaza ubuhangange bw' umuryango", Translated: "Large families are desirable because more children mean more wealth", respondent from MUNINI said. "... therefore, higher productive capability status for the family", she added. In addition, some families honored marriage as a very important thing due to payment of bridewealth in cows, goats, pigs, or money; hence some parents attempted to force children to get married in early ages. We have found young mothers between 15 - 19 years who had 2 - 4 children and others aged 20 - 24 years who had 5 - 6 children. Other families viewed more children as a way to decrease parents' workloads. They preferred girls to assist in home activities such as cooking, and boys to assist in breeding activities such as keeping cows, goats, etc. Others chose to have more sons as a way to increase financial security for parents in late ages or in crises, to show family productivity while others preferred a son as a higher social status for men.

\section{2) Spousal disapproval or other gender-based barriers}

Women non-users (5.1\%) could not seek FP services without husband's approval. They feared that husbands could have withheld affections, or they could have ended into divorce and further violence.

\section{3) Religious beliefs}

Non-contraception users, 38.5\% reported religious reasons.

Quotes illustrating some of women's comments and their religious percep- 
tions towards modern contraception:

"God doesn't want it, it's just to murder those yet to be born", a woman from BIGUGU.

"No burial site in the abdomen, contraception is killing children", a woman from MUNINI.

"Children are Gods favor, being few or many", a woman from NYARUSANGA.

"God never accepts contraceptives", woman from BIGUGU.

Christianity which was $96.8 \%$ among participants, has emerged as the first religion opposing modern methods.

\section{4) Fear of side-effects}

Fear of side-effects emerged at $28.2 \%$. Women reported discouragement by peers who previously used a modern method and had experienced side effects, for examples: "bleeding, vomiting, etc." Others have at least heard rumors, for instance, "vaginal dryness, reduced organism during sex, etc."

"It is my sister who discouraged me. She said that as I only have two children, I must not use these methods. I have to wait for at least 2 more children. Additionally, I cannot ignore what $P$ ve heard, that these things have caused cancer in women users, which is why I don't use them", a woman from BIGUGU commented.

5) Low levels of education versus number of children

Data have generally revealed low education levels: $45.4 \%$ had never studied, $45.4 \%$ had primary, $8.40 \%$ had high schools, and $0.84 \%$ had tertiary. As shown by Figure 2, the number of children significantly dropped as education levels increased. Women who had 7 or more children attended no schools or had primary schools only. Contrary, those with tertiary studies had fewer children, average 1 - 3 children.

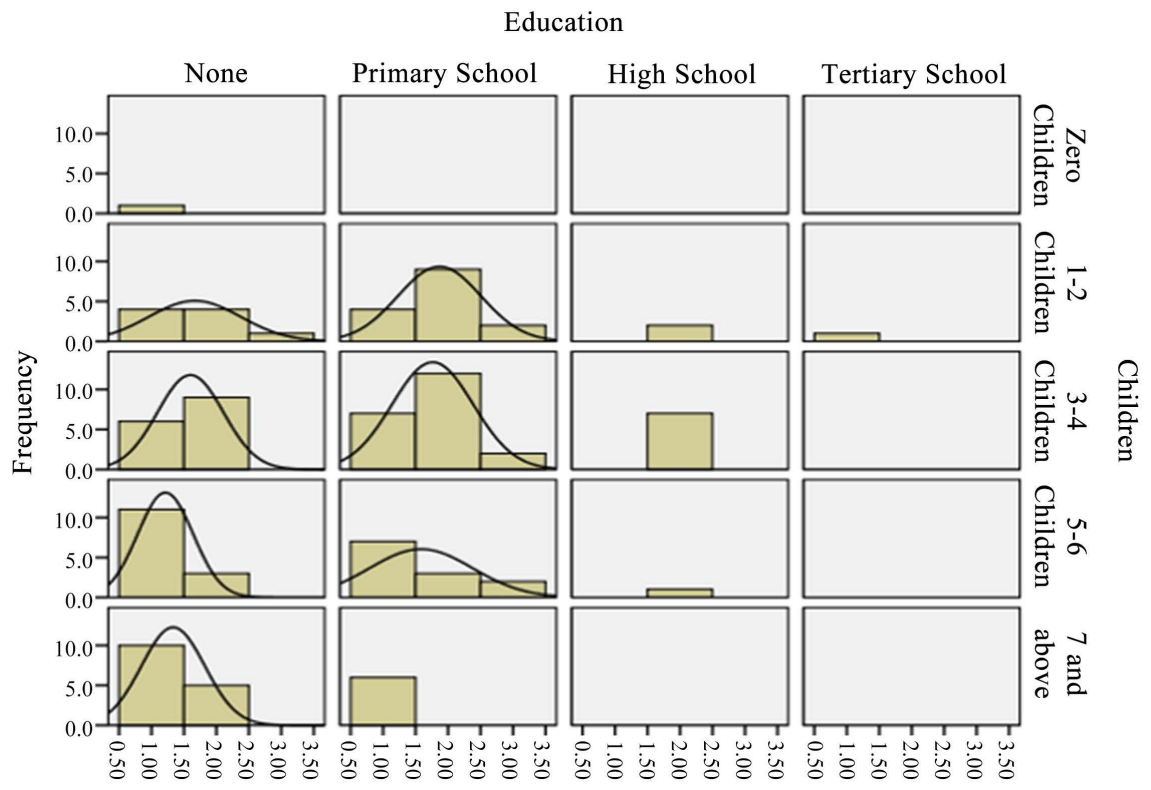

Figure 2. Represents education levels of women in households vs number of children. 


\section{6) Lack of contraception knowledge}

Only $7.7 \%$ of contraception non-users have reported lack of prior knowledge on available choices.

\section{7) Poverty}

Some families have reported financial constraints to afford their preferred methods. In addition, poverty has seen in conjunction with low education levels to have influenced women to get married at earlier ages, in their 10 's or early 20 's.

\section{General Discussion}

This study aimed at investigating factors that hinder modern contraception use in rural areas. We have, therefore, identified major barriers, ranging from social to religious to gender practices. From identified barriers, we were able to explore key factors to influence contraception uptake, and they were lately discussed in detail in this document. Nevertheless, not every rural woman denies modern contraception. We have found some who used modern methods, preferably injectables (at 44.6 percent). This finding aligns with findings seen cited sources that in Sub Saharan Africa injectables are preferred by women in areas where contraceptive prevalence is still low [8]. Sterilization methods were the least used modern method (at 3.1 percent) because these methods are irreversible, many people fear regrets that may arise in the future when they need more children. Contrary to cited sources for unmet FP in Sub-Saharan Africa, our study revealed a very low rate of contraception gap among contraception non-users. This result is doubtlessly attributable to over 45,000 Community Health Workers (CHWs) already implementing Government FP policies in Rwanda administrative villages (Imidugudu). CHWs have responsibilities including but not limited to dissemination of information FP in villages. Unfortunately, their knowledge and skills of contraception are questionable because they are not specialized FP personnel and sometimes their level of education is low, or their study background didn't include medical/health sciences. However, this finding needs farther research to assess CHWs knowledge gap on contraception and to identify their limitations. On the other side, the factors that prevented rural families from using modern contraceptive methods were dominantly originating from faith-based feelings (religion and culture). As in most cited sources widely, religions especially Christianity influence people to view contraception as killing children and therefore these persons tend to actively oppose modern methods [9]. Surprisingly, our study showed an unusual traditional method. This was described as "vaginal insertion of a clean sponge moistened in soap foam for a couple of hours post intercourse". This finding was confusing whether or not true "folkloric" methods. Folkloric methods are rarely cited in literatures and never taught in schools worldwide. Therefore, this finding needs further research to investigate the science behind these methods and to write more about folkloric methods practices [10]. 


\section{Explored Factors to Boost Family Planning Uptake in Rural Areas}

\section{1) Disrupting male engagement in family planning}

Men are often the decision makers about the desired number of children in a rural Rwandan family, yet making it difficult for women to go for FP services without husband's approval. On the other hand, men are rarely targeted in FP programs and they remain ignorant about contraceptives, hence they may force their wives to not go for FP services. However, engaging men in programming and discussions around FP issues, would be an important factor to enhance uptake especially in rural areas.

2) Convincing religious' affiliations in partnering and implementing family planning programs

In Rwanda, religious leaders have a unique advantage of being able to reach too many people every week or even more. Importantly, they are critical in human life given the number of people within their reach, dimension of holiness, their take of human beings, mind, and soul and their role as counselors. So, targeting them as partners in supporting and disseminating FP would be key to success in FP. They may influence FP in different ways, for instance, during marital counseling to couples because most couples in Rwanda go through religious weddings. They may also explain that FP does not include abortion, which is viewed negatively in Rwandan society especially by those with theological beliefs and values.

3) Involving young generations in stigmatization of high fertility-sustaining socio-cultural factors

Socio-cultural attitudes naturally affect beliefs because the basis of most attitudes depends on childhood and is generally acquired. The most important feature is that once false beliefs have developed, they are very resistant to change. In our study, as in several other studies conducted in different countries [11], most women know the methods of FP but have a lack of practice due to acquired attitudes which oppose FP actively or indirectly. In order to remove those attitudes, it is crucial to discourage the practices by letting younger generations realize those attitudes are false. This involves conducting youth friendly education and campaigns to raise their awareness on the benefits of controlling the population size. This way would work because young generations in Rwanda are receptive to change, eager to learn the truth and energetic to spread true messages widely. They are very active users of different communication channels such as the internet, entertainments, conferences, etc.

4) Increase the number of community health workers (chws) and boost their family planning knowledge of those already in service in rural villages

Majority of modern contraception users reported guidance by $\mathrm{CHWs}$. In Rwanda, CHWs help to bring information, services, and supplies to women in villages rather than frequent visits to health facilities. Unfortunately, CHWs are not specialized gynecologists to know everything, they may face a knowledge gap 
to explain certain method to women who desire to use it or give false information. On the other hand, the villages would lack enough CHWs to provide everyone with timely information or services. Therefore, the number of CHWs should be increased, with regular training to boost their knowledge and skills just to keep them updated and to mitigate risks of rumors.

\section{5) Increasing literacy and numeracy: delay family formation}

In our study, the educated participants had fewer children. This is true because literacy may reduce fertility rates in different ways. First, it works on delaying family formation (people become busy with studies) which in turn increases age at first birth. Second, it improves job prospects i.e. alleviation of poverty which itself leads to higher unmet FP. Importantly, as one is educated, it is easier to use intellectual reasoning to understand benefits coming out from good spacing of children [12].

6) Lowering the costs of modern methods or make them free for poor and needy people

Although this study did not deepen the cost analysis for different methods, another barrier to modern contraceptive use was a cost; especially for those who did not have health insurances, locally known as Mutuelle de santé. This was cited most frequently in connection with "implant"; which is the preferred method for rural women, but the price is high without insurance. Few methods are not available in rural settings in Rwanda for several reasons including limited number of specialized workers, and from the client's perspective, many cannot afford associated costs. So, contraceptive costs should be lowered or even made free, and specialized FP services should be decentralized.

\section{7) Mass media campaigns}

We have seen women who reported a contraception information gap, otherwise would have controlled their births. Some did not use contraception because of reasons that included lacking information of the full range of contraceptive methods, or challenges in accessing contraception. However, mass media campaigns would have potential to provide useful information on the benefits and logistics of FP and influence social norms around such contentious topics at almost zero cost.

\section{Limitations}

The study was limited to 119 households in 3 research areas only. Though, it may reflect what factors affect family planning in rural areas, it cannot represent the whole rural areas. The articles we studied, and the general resources are identical in the proportion of studies with trusted outcomes published from studies done in similar study settings. However, our results were similar and consistent with those reported in most literatures. We thoughtfully posed questions and delivered in a way that allowed respondents to their true feelings without distortion. We targeted participants in one-on-one approach that helped to avoid yeah-saying and friendliness biases that were the most expected biases. No farther biases identified. 


\section{Conclusion}

Social and religious beliefs, poor education and spousal disapproval are major factors to poor uptake of modern contraception in rural areas. These factors would be overcome through approaches targeting religious leaders and men as key FP partners. In addition, provision of alternative education such as vocational training to illiterate and unemployed young people would improve their literacy and numeracy skills to enhance employability opportunities and prolong the age of first birth. Moreover, media campaigns would potentially provide useful information on benefits and logistics of contraception in the population.

\section{Acknowledgements}

This paper and research behind it would not have been possible without ethical clearance of the Research and Institutional Review Board (IRB) of College of Medicine and Health Sciences-University of Rwanda (UR), thanks to Prof. Jean Bosco GAHUTU, IRB Chairperson. We highly acknowledge the exceptional support of our supervisors, Dr. Vincent K. Cubaka and Dr. Richard Nduwayezu. Their enthusiasm, knowledge and exacting attentions to details have been an inspiration and kept the work on track. Thanks to Dr. Martin Ndinzwenimana who actively helped in data collection and writing up the manuscript, and Dr. Nsabimana Claude and Dr. Munyamisugi who provided technical support for this work to happen.

\section{Funding}

This study received no specific grant from any funding agency in the public, commercial, or not-for-profit sectors.

\section{Conflicts of Interest}

The author declares no conflicts of interest regarding the publication of this paper.

\section{References}

[1] Phil, M.T.M.D. and Phillips, S.J. (2014) Family Planning: Choices and Challenges for Developing Countries. Best Practice \& Research Clinical Obstetrics \& Gynaecology, 28, 931-943. https://doi.org/10.1016/j.bpobgyn.2014.04.014

[2] Cleland, J., Conde-Agudelo, A., Peterson, H., Ross, J., et al. (2012) Contraception and Health. The Lancet, 380, 149-156. https://doi.org/10.1016/S0140-6736(12)60609-6

[3] Cleland, J.G., Ndugwa, R.P. and Zulu, E.M. (2010) Family Planning in Sub-Saharan Africa: Progress or Stagnation?

[4] Haub, C. and Kaneda, T. (2014) 2014 World Population Data Sheet [Internet].

[5] Family, K.S. (2008) Family Planning in Rwanda (How a Taboo Topic Became Priority Number One).

[6] Snapshot, C. (2019) Rwanda Actions for Acceleration (Rwanda's FP2020 Priorities). 
1-7.

[7] Impact, A.H. (2017) Family Planning 2020 Commitment Govt. of Rwanda 2017-2019.

[8] Mar, D.J. (2013) Trends in Contraceptive Use. Contraception, 87, 259-263. https://doi.org/10.1016/j.contraception.2012.08.029

[9] Konje, J.C. and Ladipo, O.A. (1999) Barriers to Uptake and Use of Modern Methods of Contraception in Developing Countries. International Journal of Gynecology \& Obstetrics, 65, 287-294. https://doi.org/10.1016/S0020-7292(99)00052-1

[10] Singh, S., Darroch, J.E. and Ashford, L.S. (2014) Adding It up: The Costs and Benefits of Investing in Sexual and Reproductive Health 2014.

[11] Cleland, J., Harbison, S. and Shah, I.H. (2014) Unmet Need for Contraception: Issues and Challenges. Studies in Family Planning, 45, 105-122. https://doi.org/10.1111/j.1728-4465.2014.00380.x

[12] UNFPA, WHO (2002) Report of a Technical Consultation on Sexual Health. Sexual Health Document Series, Geneva, 28-31 January 2002. 